\title{
Simulation Model of an Autoclave Operation Using iThink Software
}

\author{
Elena Muravyova \\ Branch in Sterlitamak \\ Ufa State Petroleum Technological University \\ Sterlitamak, Russian Federation \\ muraveva_ea@mail.ru
}

\author{
Sergey Shokurov \\ Branch in Sterlitamak \\ Ufa State Petroleum Technological University \\ Sterlitamak, Russian Federation \\ shokurov-sergei@mail.ru
}

\begin{abstract}
This research paper is focused on temperature control in an autoclave used for the production of slag blocks from ash and slag materials of heat and power plants. This is done in order to increase the autoclave performance, reduce the amount of rejects in the finished slag blocks, increase the quality of slag blocks and optimize the consumption of energy resources. To solve this problem, it is proposed to use the simulation model of the autoclave in iThink simulation software package with the simultaneous supply of saturated steam not only through one pipe, but through several pipes. This allows to heat up the entire volume of the autoclave more evenly and adjusts the steam supply based on the uniformity of heating-up of slag blocks subject to the constantly changing chemical composition of raw materials. Using this model, depending on a number of input parameters, it is possible to simulate the autoclave operation process by displaying the operation dynamics in graphical form over time, as well as simulate the mutual influence of control loops on each other without spending a lot of time and resources. The paper also provides an analysis of the obtained experimental model, which allows us to assess the performance capability, adequacy and effectiveness of the model.
\end{abstract}

Keywords-autoclave, valve, pipeline, temperature, control, simulation.

\section{INTRODUCTION}

In real conditions, conducting experimental research is time-consuming and unprofitable in terms of resources. As well as analyzing the influence of various factors in full can lead to emergencies. In this regard, such studies are carried out in a simulation environment of software modeling. This approach allows us to fully study the impact of various factors and reduces consumption of time and resources.

The authors needed to develop an autoclave simulation model, which depending on several input parameters, allowed them to simulate an autoclave process with a graphic display of the operation dynamics hour by hour and simulate the mutual influence of control loops on each other.

During the development of the model, available data on the manufacture of slag blocks produced from ash and slag materials of thermal power plants (Kumertau CHP plant) was used. The mutual influence of the control loops in the autoclave was also taken into account.

The model was created using iThink simulation software. The analysis of the obtained model was prepared in order to assess its adequacy and performance.

\section{Conceptual Model of An Autoclave for the PRODUCTION OF SLAG BLOCKS}

The analysis of the results obtained during the experimental studies of slag blocks production from ash-andslag materials of thermal power plants (including Kumertau CHP plant) using brown coal as a fuel shows that existing process equipment and layout do not allow to obtain finished products of the required quality [1]. This is being hindered by the following main reasons: large fluctuations in the content of iron oxides in ash and slag materials $(3 \div 27) \%$ resulting in a random duration of temperature/pressure rise/fall stages in the autoclave [2], as well as of isothermal exposure at constant pressure for autoclave process cycles; in existing autoclaves saturated steam is supplied through a single pipe [3] which does not allow to uniformly heat the entire volume of the autoclave which as a result increases the amount of rejects among the finished slag blocks; in the existing process of slag blocks production, the acceptable autoclave rise and fall periods of temperature and pressure are constant average parameters that do not take into account the chemical composition of raw material which varies from batch to batch. Generally, their value is overestimated which leads to a decrease in autoclave performance, decrease in quality of slag blocks and the excessive consumption of energy resources.

To reduce the amount of rejects among the slag blocks subjected to heat and moisture treatment in the autoclave, it is proposed to feed the steam into the autoclave simultaneously by several pipes (aiming to uniformly heat the entire working space of the autoclave). It is obvious that the more such pipes are there, the more uniform the heating will be and there will be less heat loss.

Figure 1 shows the dependence of amount of rejects $(\mathrm{Re})$ and thermal energy consumption $(\mathrm{Q})$ on number of points $(\mathrm{n})$ of steam supply to the autoclave. It follows from the figure that the reduction in amount of rejects $(\mathrm{Re})$ among the finished product after the heat-moisture treatment of slag blocks almost stops at $n>6$, and energy consumption - at $n>$ 5. Therefore, from an economic point of view, a further increase in steam supply points to the autoclave does not make sense, and on this basis it was decided to supply steam to the autoclave through six pipes [3].

The design of the autoclave is shown in Figure 2 (without elements that are not directly related to the control system). It is a cylindrical body 1 , the ends of which after the autoclave is being loaded with slag blocks are sealed with covers 2 . 


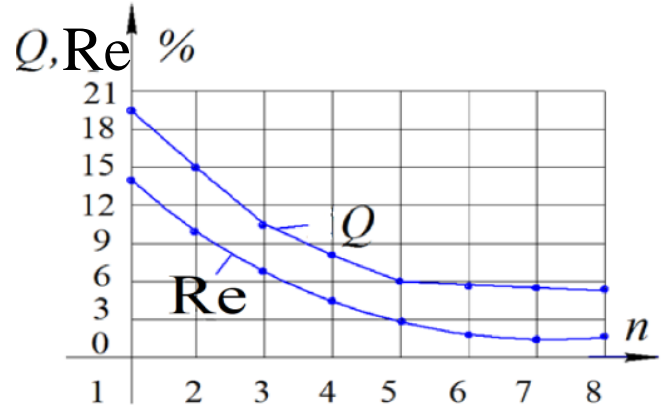

Fig. 1. Amount of rejects (Re) and energy consumption (Q) as a function of steam supply points (n)

Their closing is controlled by GS1 to GS4 travel sensors [4]. A typical drain system of a batch-type autoclave consists of pipes $3,4,5$ and valve 6 .

Steam is supplied to the autoclave through pipe 7 and a valve with manual actuator $\mathrm{F} 1$, as well as through a control valve $\mathrm{F} 2$. To the control valves $\mathrm{F} 5 \div \mathrm{F} 7$, steam is supplied through valve F3, and to the control valves F8 -F10 - through valve F4. Steam is supplied to the upper and lower parts of the autoclave via valves (F5 - F7) and (F8 - F10), respectively. The pressure in the autoclave is controlled by pressure gauges 8 , and the temperature at six points is measured by sensors (T5 - T10). Steam from the autoclave is discharged through the control valve F11 and the pipe 9.

To prevent overpressure in the autoclave, at the "Blow off" process stage, the pipes 7 and 9 have the same crosssection, and pipes that come from valves F3 and F4 the crosssection is two times smaller. For the same reasons, the cross section of pipes supplied to the valves (F5 - F10) is $1 / 6$ of the cross section of pipe 7 .

The proposed autoclave design, thanks to steam supply and temperature control in six points, allows to more uniformly and in less time to provide the necessary temperature and pressure to the autoclave.

This design allows the optimal periods of rising/falling of pressure/temperature in the autoclave to be controlled not by an a priori set constant time interval, which in most cases does not correspond to the constantly changing chemical composition of the raw material, but by the uniformity of heat-up of the slag blocks. Thus, fundamentally new opportunities are created to reduce energy consumption and improve the quality of finished products during the production of slag blocks from ash and slag materials of $\mathrm{CHP}$ plants using brown coal.

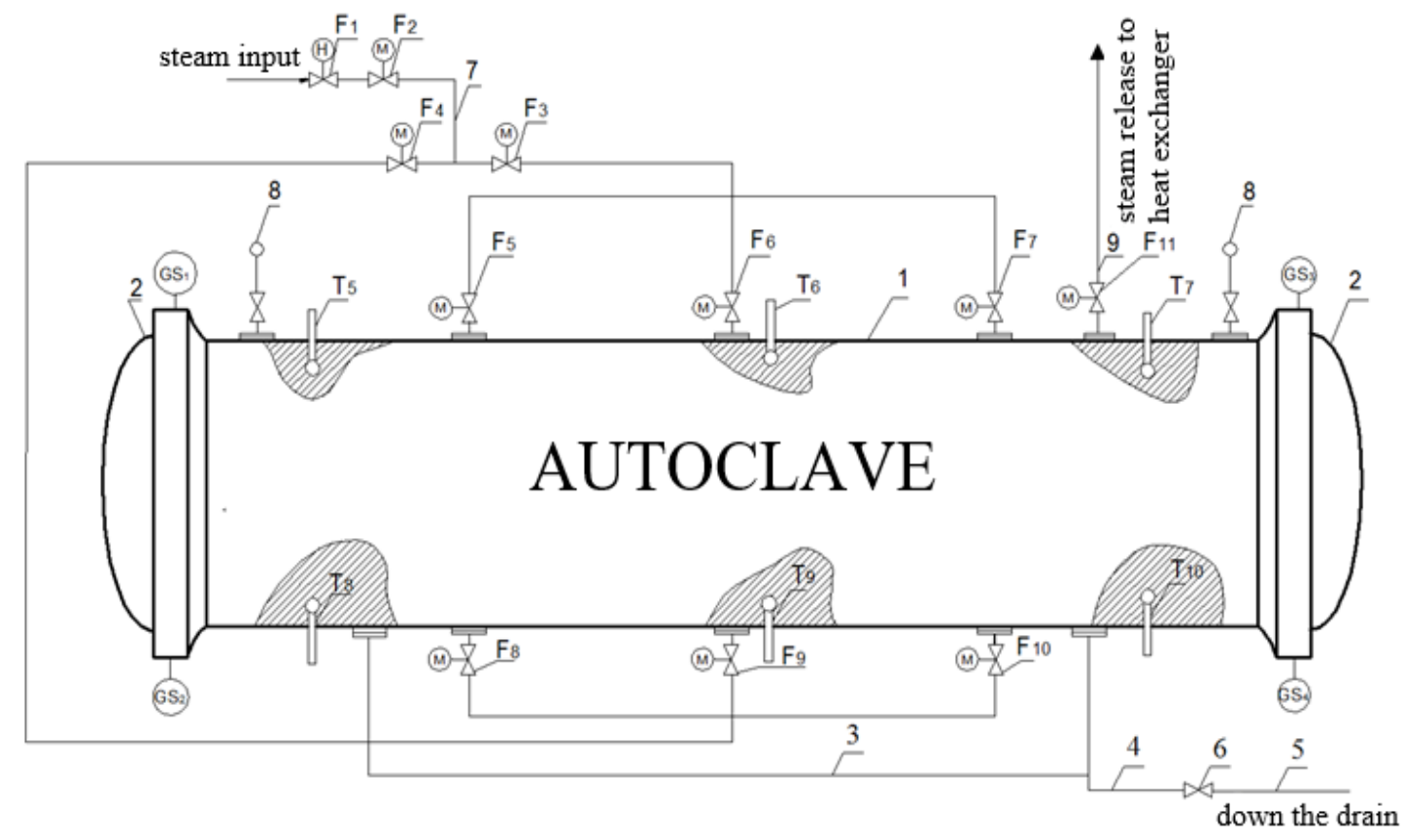

Fig. 2. Design of the autoclave for the production of slag blocks from ash-and-slag wastes

\section{Simulation of Slag Blocks Production}

Process IN AN AUTOCLAVE IN ITHINK ENVIRONMENT

Visualization of object domain in iThink is done using classic cognitive maps [5]. Models in iThink are represented by two hierarchical levels: the model level and the code level.

During simulation process, a structural diagram of the model is formed from the built-in building blocks in the model window. Then, the interconnections are established between them by means of arrows-connectors; program code is automatically generated. The operator needs only to enter functional dependences and values, after that the model is ready to start. Formulas and parameter values are set using standard iThink dialog boxes [6].

The model uses a type of structural blocks which is depicted as a figure consisting of a path and a valve, called a flow. Flow is a process that proceeds continuously in time which can be assessed in physical or monetary units correlated with any time interval (rubles per month, litres per hour, etc.) [7]. In this model, two flows are used: "pipeline" and "exit". 


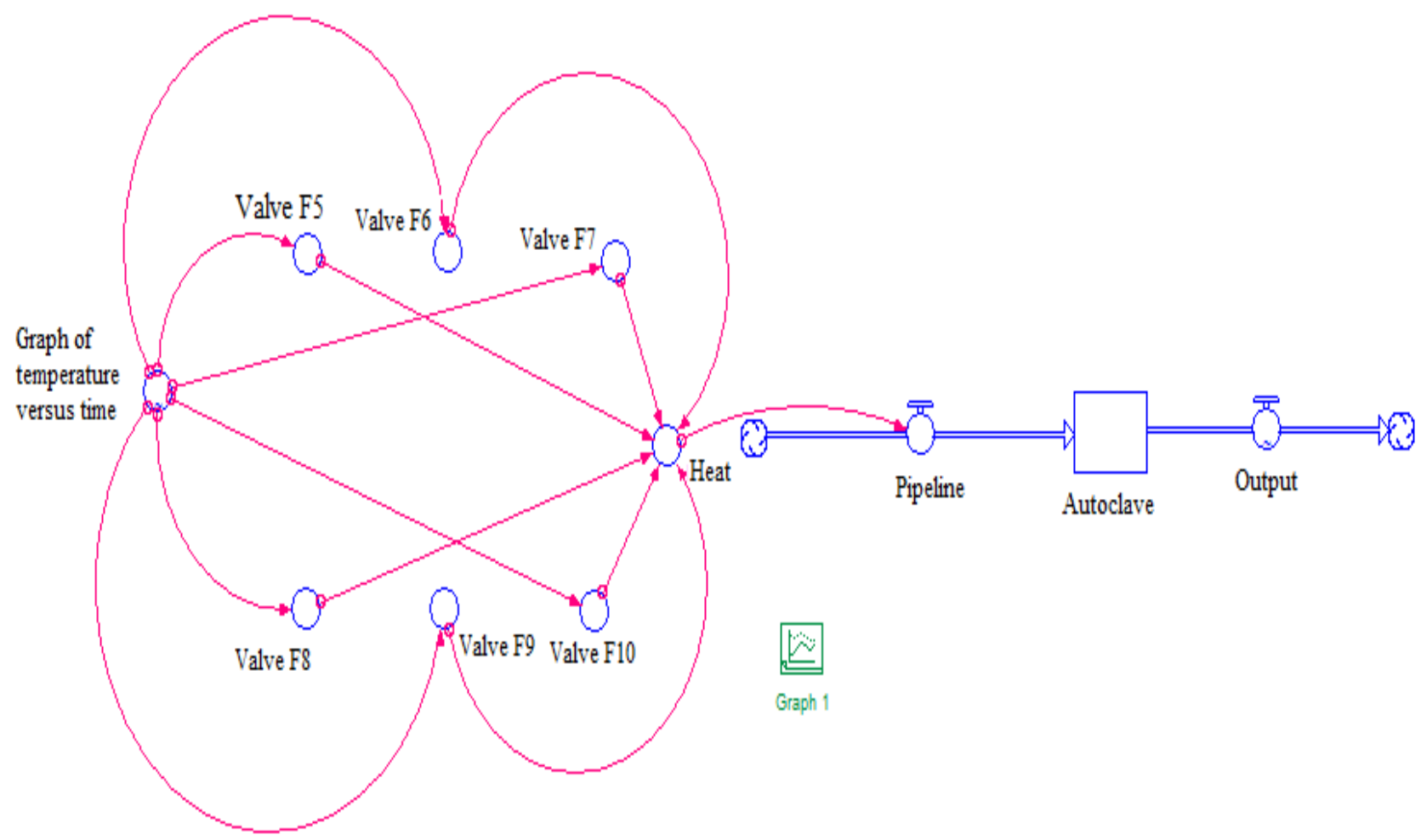

Fig. 3. General view of autoclave model in "Model" tab

\section{Description of AutOclave MOdEL}

When creating the "Autoclave" model, a graphic function "Temperature vs. Time Graph" (Figure 4) was assigned. In iThink system it is specified by converters that use graphic functions being sketches of the relationship between specified input and output parameters. Input and output parameters can be entered directly on the graph itself by drawing an experimental curve [8].
The "Temperature vs. Time Graph" converter sets and adjusts the temperature for 12 hours (Figure 4). During the process, the steam temperature varies with time. From the graph it is seen that the temperature rises first from 0 to the maximum value of $190^{\circ} \mathrm{C}$, then this temperature is maintained for 9 hours. Then the temperature drops to $60^{\circ} \mathrm{C}$, and the final stage of autoclave operation is the discharge of the product.
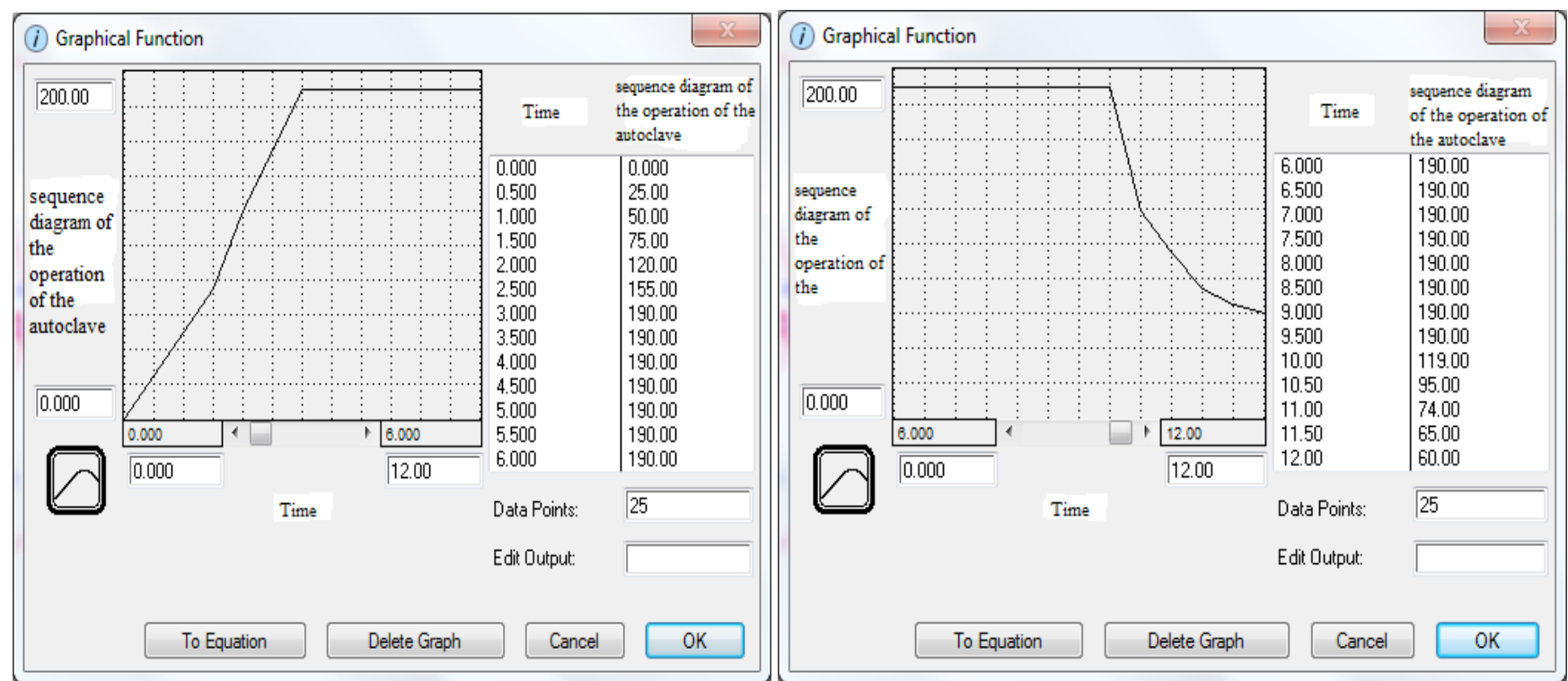

Fig. 4. "Graphical Function" window of the "Temperature vs. Time Graph" converter 
From the converter "Temperature vs. Time Graph" the steam is supplied through pipelines controlled by valves F5, F6, F7 and F8, F9, F10 to the converter "Heating" as shown in Figure 3. This converter is designed to set the temperature so that it does not exceed the maximum value, which is equal to $190^{\circ} \mathrm{C}$. Figure 5 shows the configuration of this converter.

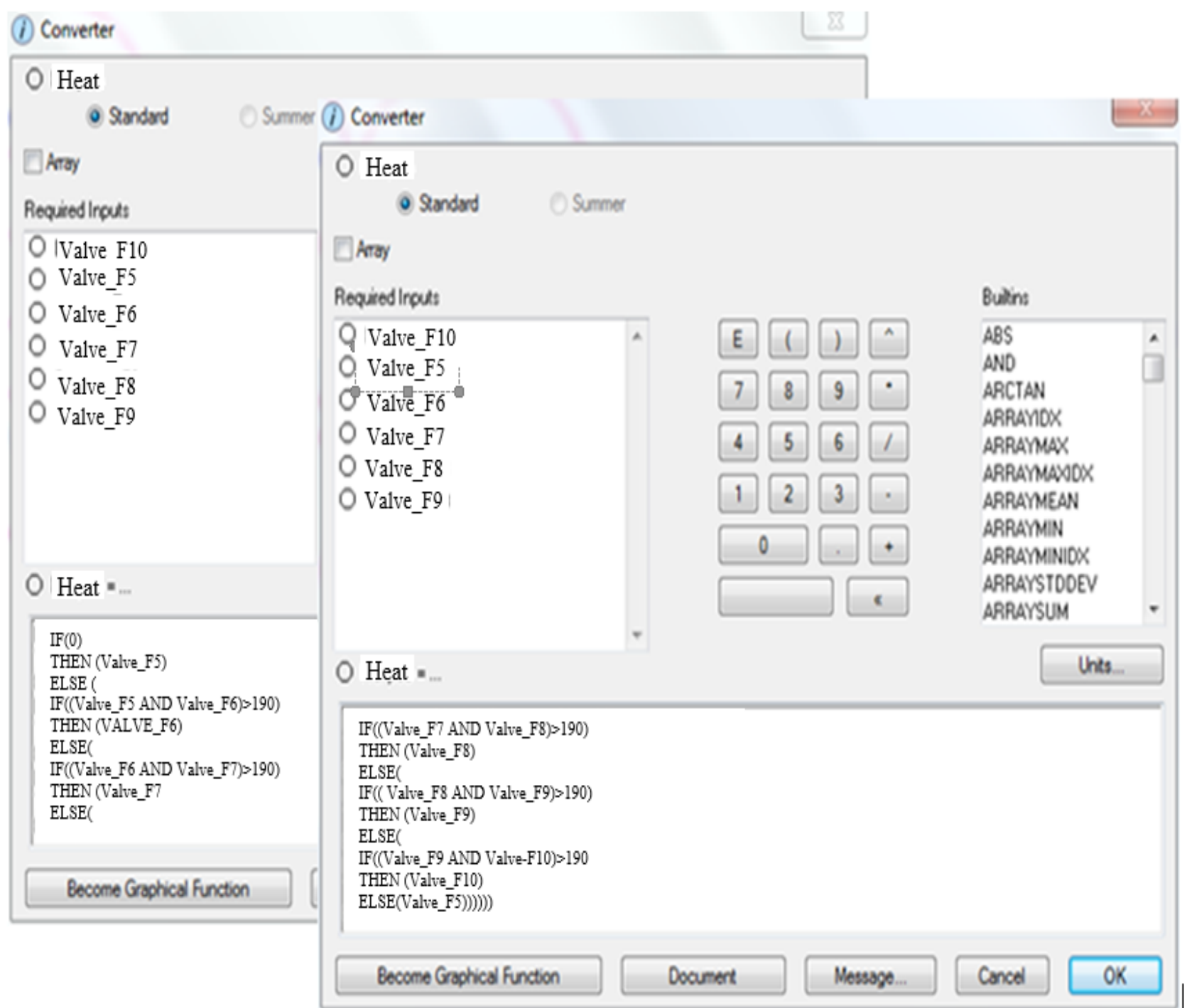

Fig. 5. Setting the "Heating" converter

The "Heating" converter transmits temperature value of the supplied steam into the "Pipeline" flow shown as a path with a valve. Below is the setting of this flow:

$$
\text { Pipeline }=\text { Heating. }
$$

The "Pipeline" flow allows transferring the steam temperature received from the "Heating" converter to the "Autoclave" unit continuously in time. The block "Autoclave" remembers the received temperature values. The block is configured as follows:
The completion of the process occurs at temperatures below $50^{\circ} \mathrm{C}$. The autoclave transfers this temperature to the "Exit" flow.

$$
\text { Exit }=50 \text {. }
$$

In the "Equation" tab all made settings are automatically displayed on the program code level. You can also set the units of measurement, notes on parameters and formulas for simulation (Figure 6).

\section{INT Autoclave = Pipeline.}




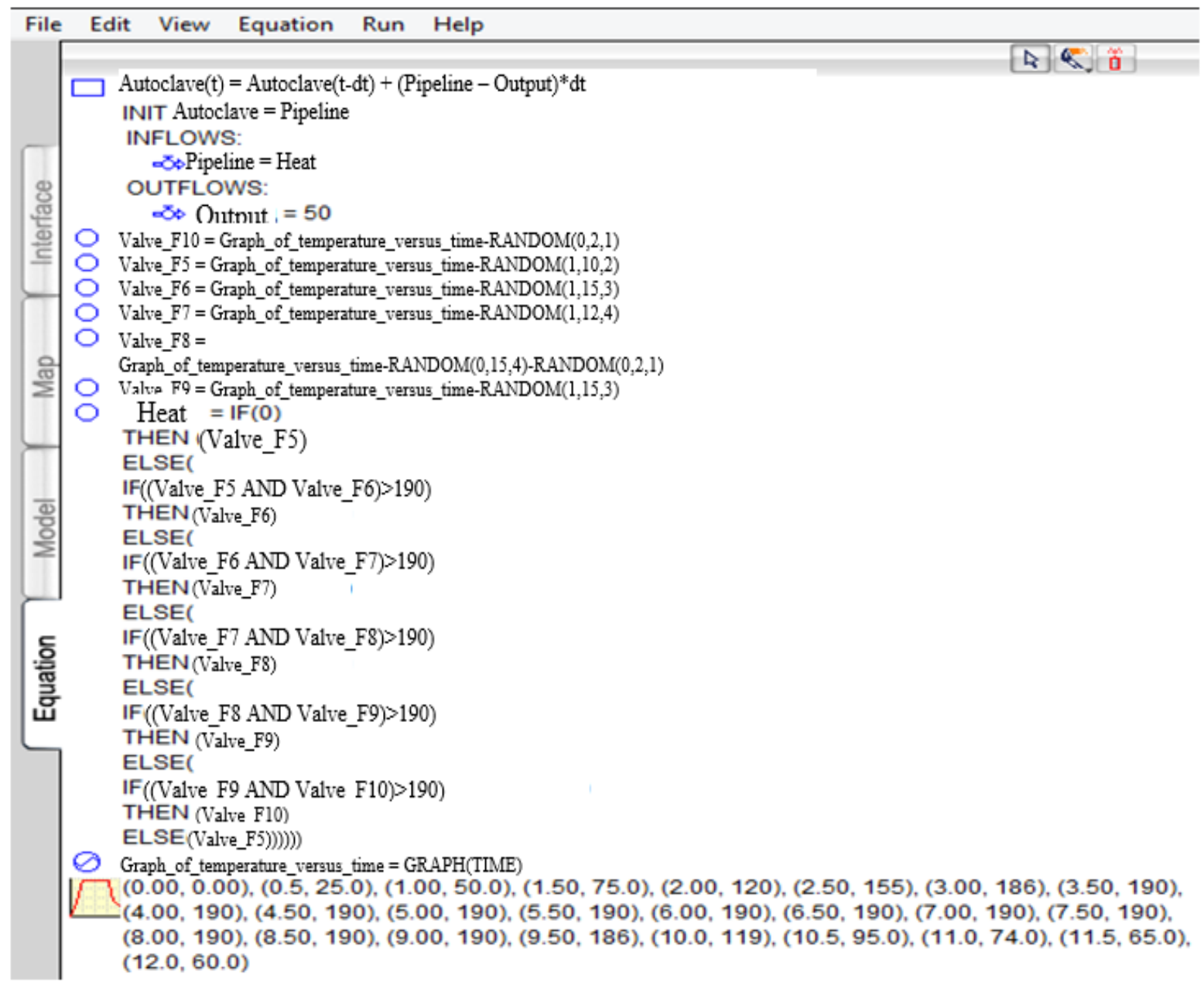

Fig. 6. "Equation" tab

After the launch of the process, according to the simulation results, the following statistics were obtained, presented in Figure 7.

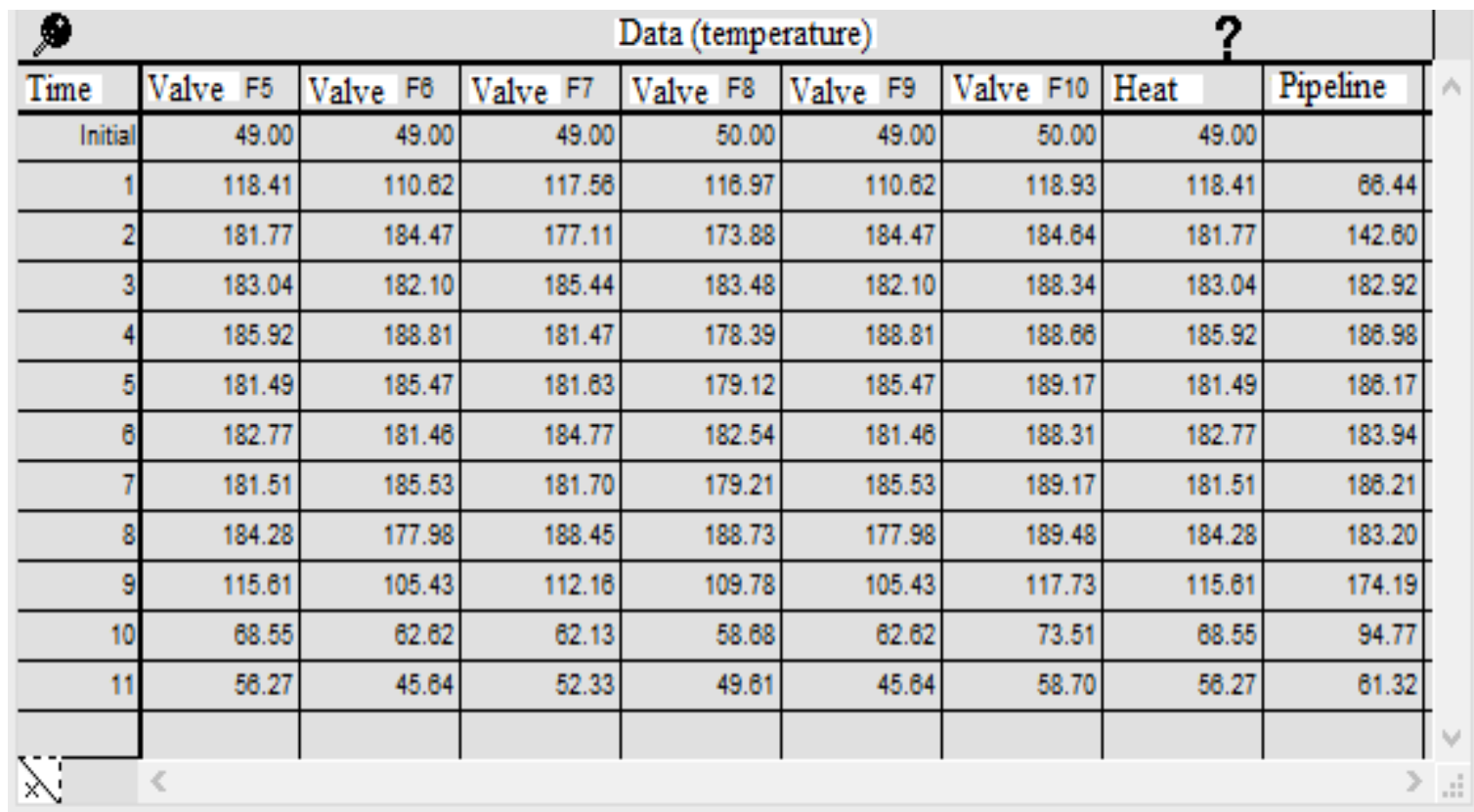

Fig. 7. Table of autoclave control parameters 


\section{AnAlysis OF THE RESUlting MODEL}

The temperature in the autoclave which should not exceed a maximum value of $190^{\circ} \mathrm{C}$ has a significant effect on the production of slag blocks. When the maximum temperature is reached, the valves through which steam is supplied are closed and the temperature decreases. In order to avoid rejects during the production of slag blocks, the temperature in the autoclave at the isothermal cure stage should not be below $175^{\circ} \mathrm{C}$, based on this, when the minimum temperature is reached, the valves open again.

In the autoclave, when controlling the steam flow through different valves, there is a mutual influence of the control loops on each other. On the basis of the obtained model, we will analyze the specified mutual influence of the control loops on each other [8]. Let us consider 5 different modes of autoclave operation:
- steam supply through all valves;

- $\quad$ steam supply through valves F5, F8;

- $\quad$ steam supply through valves F5, F6, F7;

- $\quad$ steam supply through valves F6, F9;

- steam supply through valves F5 и F10.

Let us consider the 1st mode of autoclave operation. In this case, steam is supplied through valves F5, F6, F7, F8, F9 and F10. In this mode, the heating of the autoclave inner space occurs evenly. The readings of all temperature sensors T5, T6, T7, T8, T9 and T10 fluctuate around $190^{\circ}$ $\mathrm{C}$ (Figures 8,9$)$. This is a benchmark mode of autoclave operation.

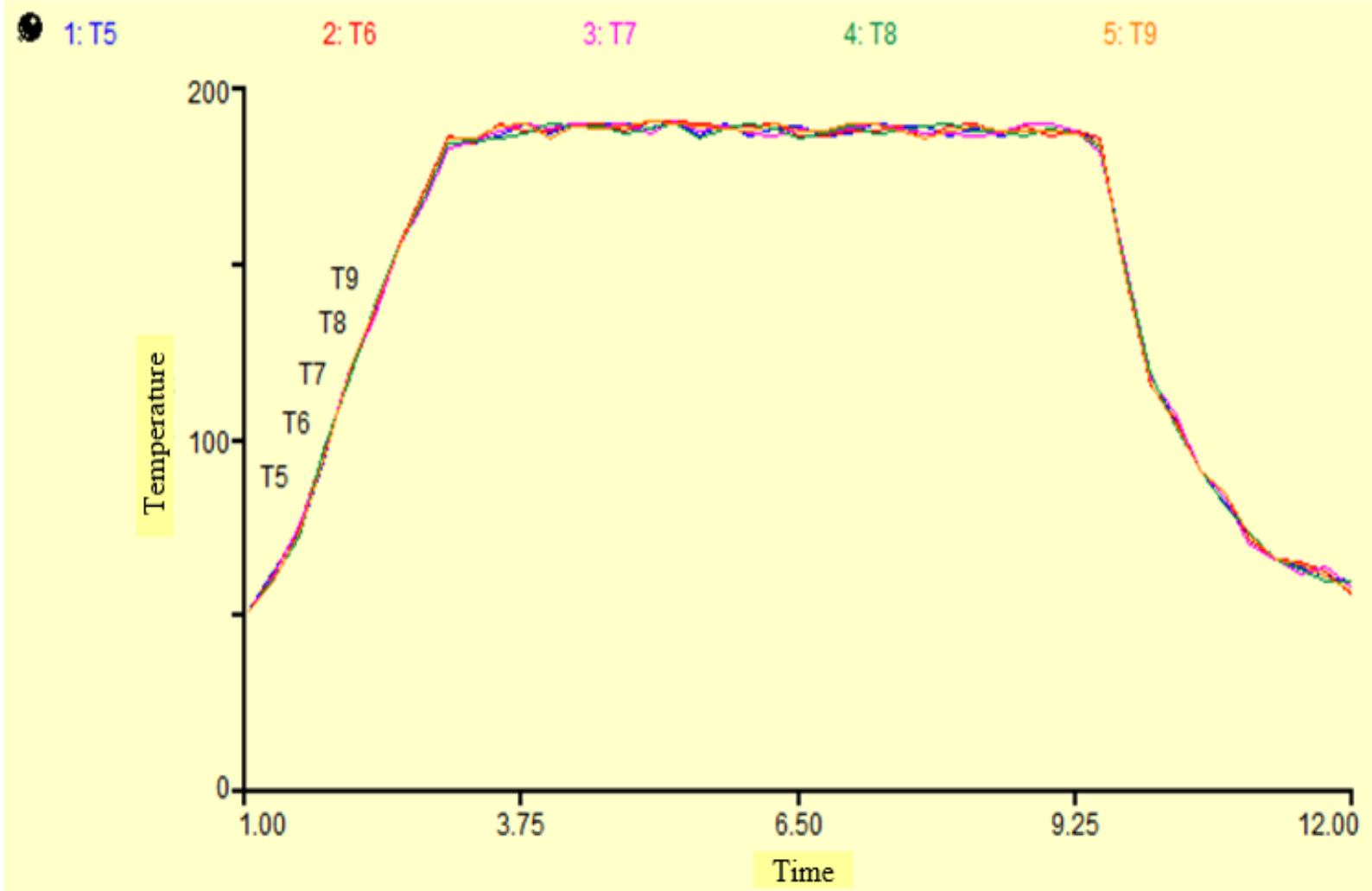

$\nabla \quad ?$

Fig. 8. Mode of autoclave operation with open valves F5 - F9

Let us consider the 2nd mode of autoclave operation when steam is supplied by pipelines through valves F5 and F8; valves F6, F7, F9 and F10 are closed. The steam supply is continued until T5 and T8 sensors show a temperature of $190^{\circ} \mathrm{C}$. The autoclave space next to the sensors T6, T7, T9 and T10 will heat up more slowly than the space next to the sensors T5 and T8. In the simulation, the temperature sensors $\mathrm{T} 6$ and $\mathrm{T} 9$ showed a temperature of $182^{\circ} \mathrm{C}$, and the sensors $\mathrm{T} 7$ and $\mathrm{T} 10$ showed a temperature of $179^{\circ} \mathrm{C}$. After 2 hours and 30 minutes, the temperature in the entire space of the autoclave became equal to $190^{\circ} \mathrm{C}$ (Figure 10). 
Q 1:T6

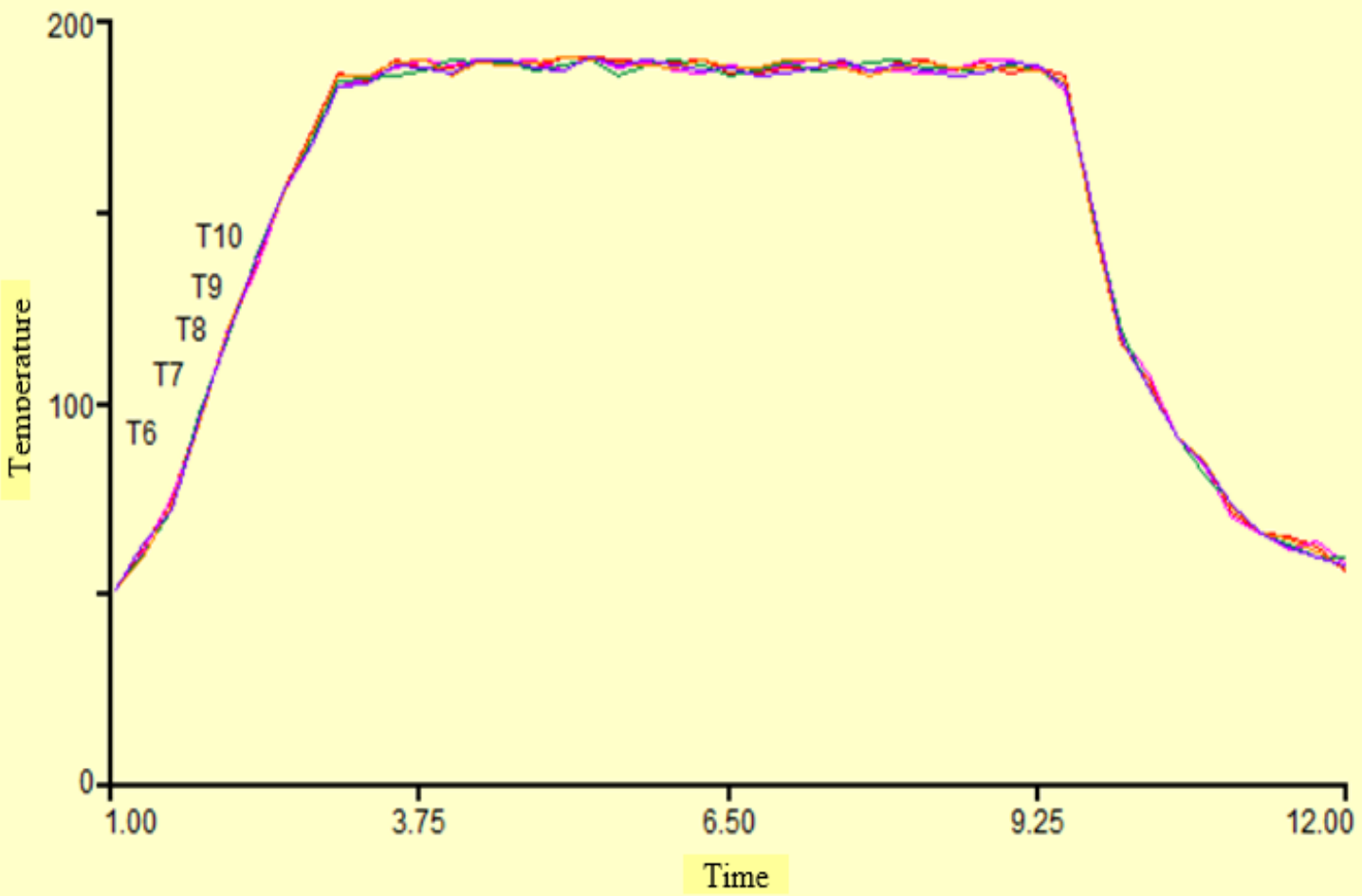

$\nabla$

\section{?}

Fig. 9. Mode of autoclave operation with open valves F6 - F10
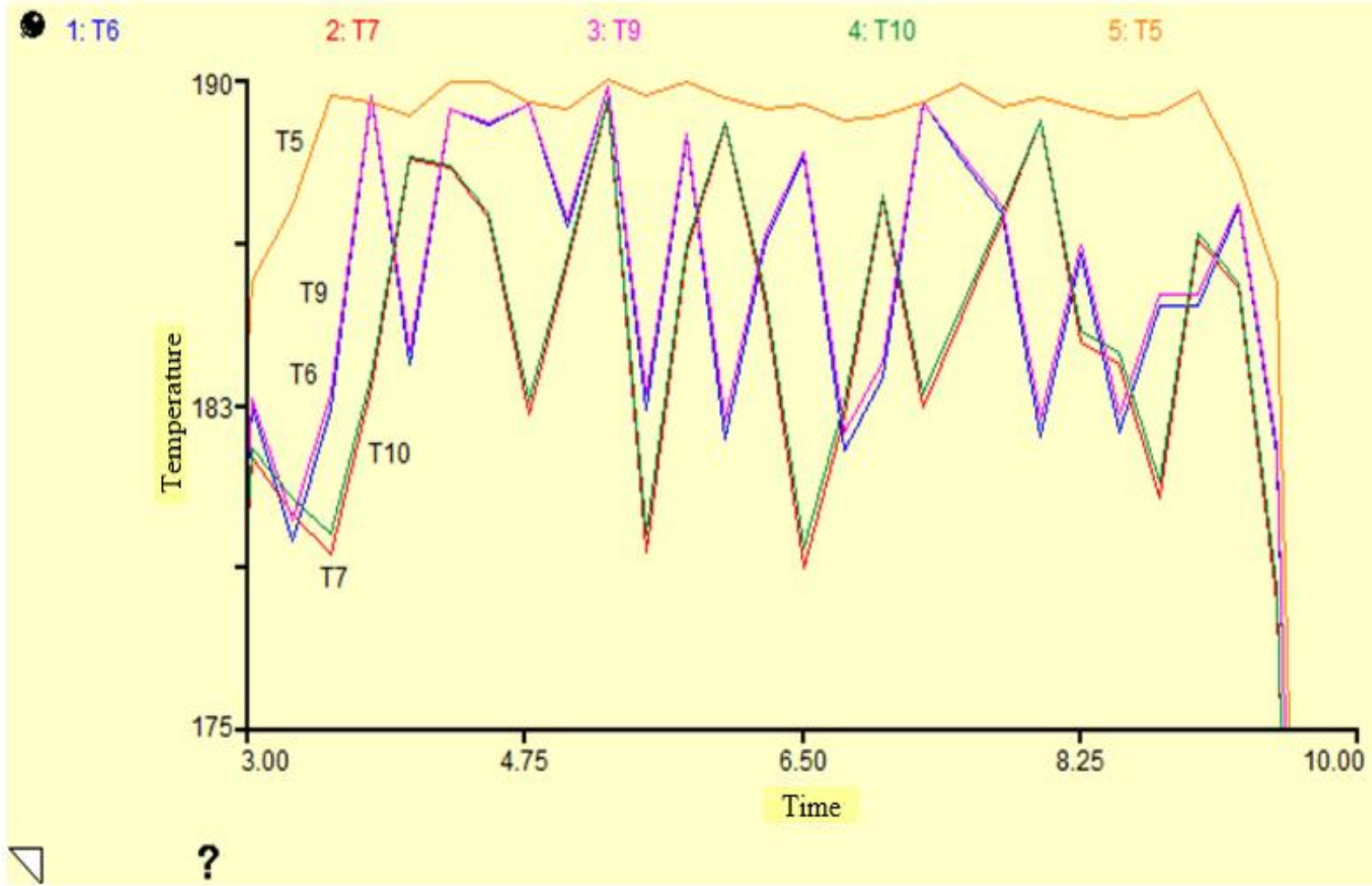

$?$

Fig. 10. Mode of autoclave operation with open valves F5 and F8 
Let us consider the 3rd mode of autoclave operation. In this mode, steam is supplied by pipelines through valves F5, F6 and F7; valves F8, F9 and F10 are closed. In this mode, steam is supplied to the upper part of the autoclave until a temperature of $190^{\circ} \mathrm{C}$ is reached which is detected by sensors T5, T6 and T7. The autoclave space with the T8, T9 and T10 sensors will heat up more slowly than the space next to the T5, T6 and T7 sensors. In the simulation, the temperature sensors T8, T9 and T10 showed a temperature of $188^{\circ} \mathrm{C}$. After 1 hour, the temperature in the whole space of the autoclave became equal to $190^{\circ} \mathrm{C}$ (Figure11)

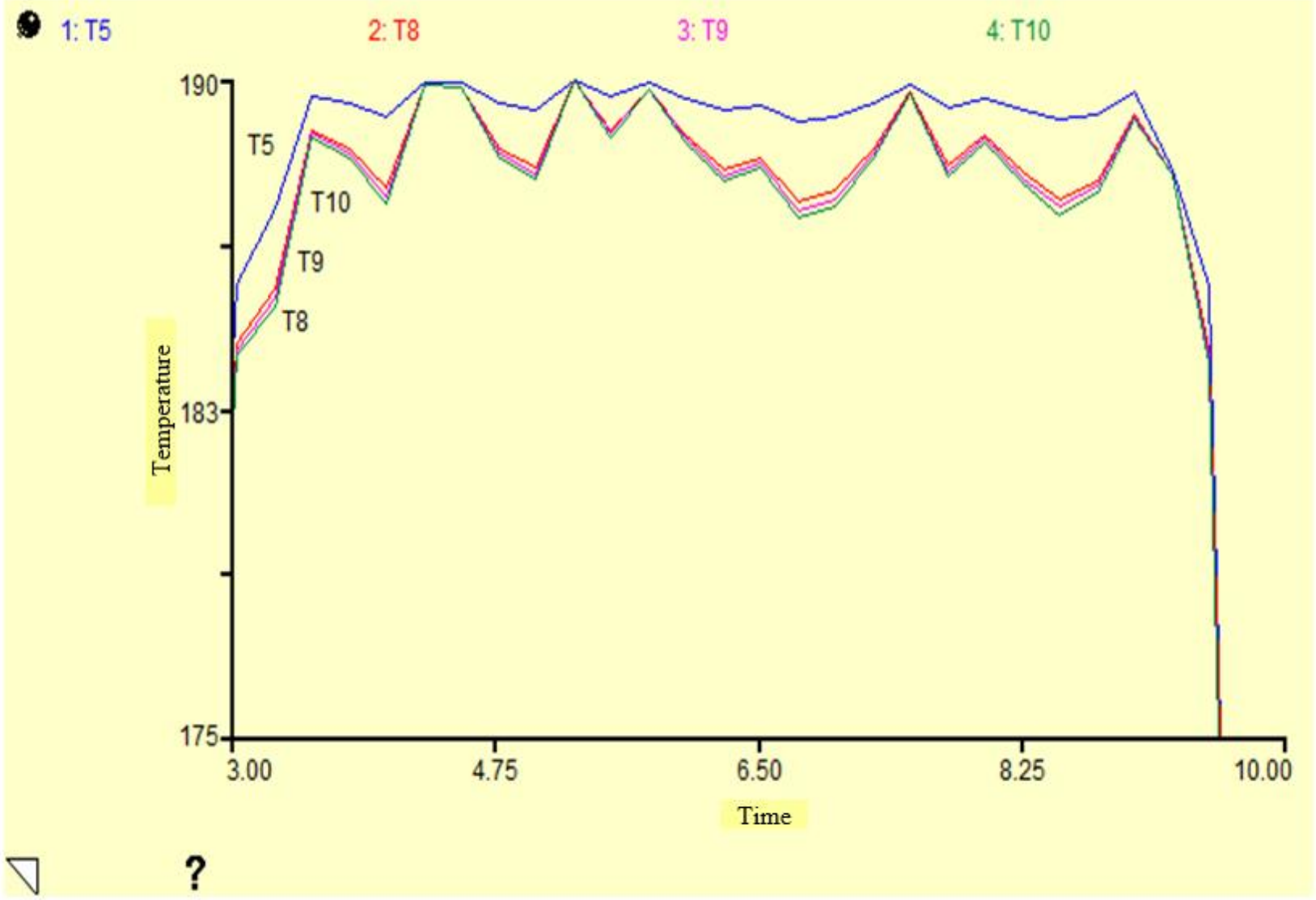

Fig. 11. Mode of autoclave operation with open valves F5, F6 and F7

Let us consider the 4 th mode of autoclave operation. In this mode, steam is supplied by two pipelines through the valves F6 and F9; valves F5, F7, F8 and F10 are closed. Steam is supplied to the middle part of the autoclave until the T6 and T9 sensors show a temperature close to the maximum value of $190^{\circ} \mathrm{C}$. The autoclave space with the T5, T7, T8 and T10 sensors will heat up more slowly than the space next to the T6 and T9 sensors. In the simulation, the temperature sensors $\mathrm{T} 5$ and $\mathrm{T} 8$ showed a temperature of $185^{\circ} \mathrm{C}$, and the sensors $\mathrm{T} 7$ and $\mathrm{T} 10$ showed $184^{\circ} \mathrm{C}$. After 1 hour and 30 minutes the temperature in the whole space of the autoclave became equal to $190^{\circ} \mathrm{C}$ (Figure 12).
Let us consider the 5th mode of autoclave operation. In this mode, steam is supplied by two pipelines through the valves F5 and F10; valves F6, F7, F8 and F9 are closed. Steam is supplied to the left upper and right lower parts of the autoclave until the sensors T5 and T10 show a temperature equal to the maximum value of $190^{\circ} \mathrm{C}$. The autoclave space with T6, T7, T8 and T9 sensors will heat up more slowly than the space next to T5 and T10 sensors. In the simulation, the temperature sensors T6 and T8 showed a temperature of $182^{\circ} \mathrm{C}$, and the sensors $\mathrm{T} 7$ and T9 showed $183^{\circ} \mathrm{C}$. After 2 hours, the temperature in the whole space of the autoclave became equal to $190^{\circ} \mathrm{C}$ (Figure 13). 
Q 1:T5

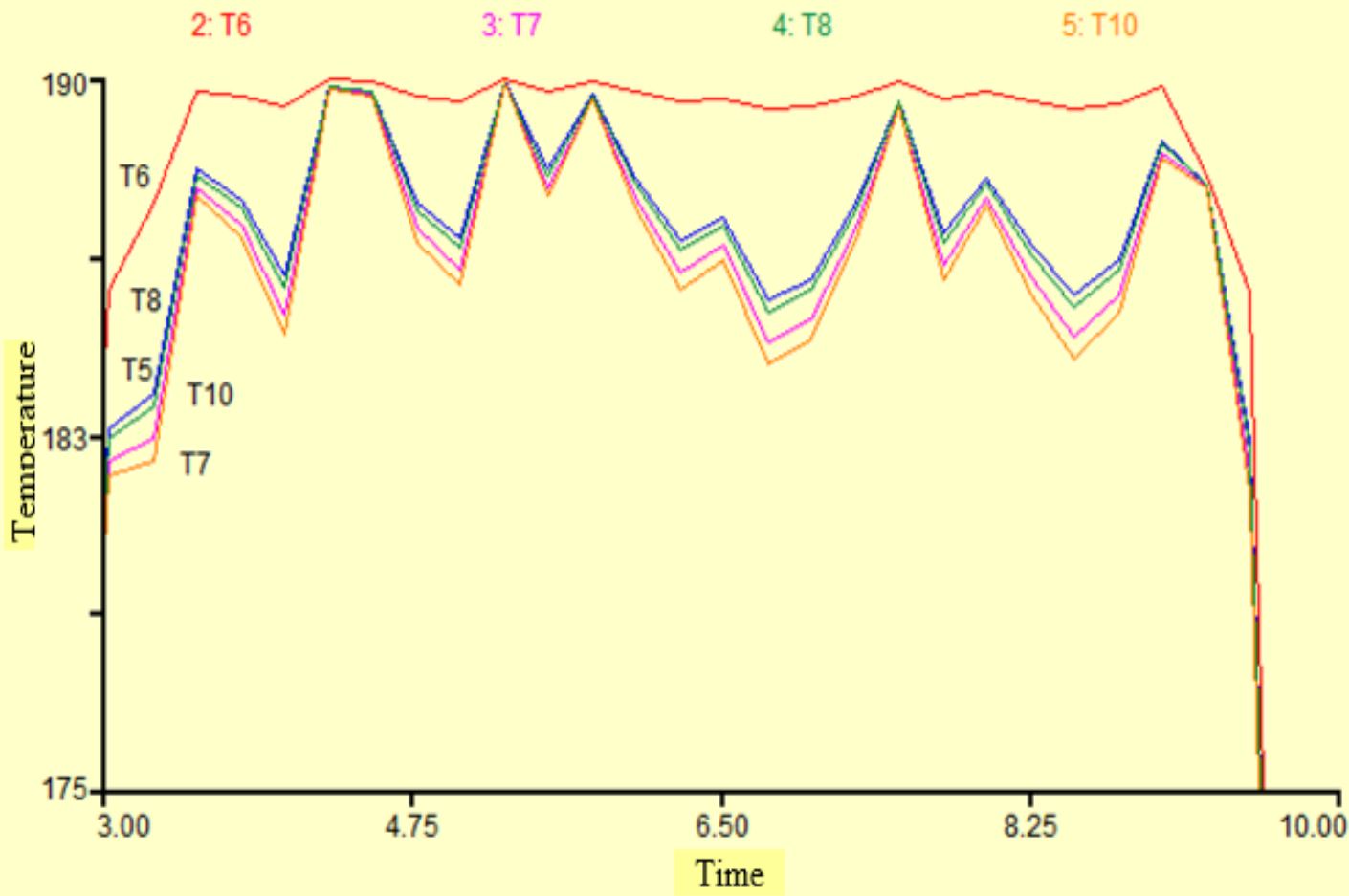

$\nabla$

\section{$?$}

Fig. 12. Mode of autoclave operation with open valves F6 and F9

9 1: T5

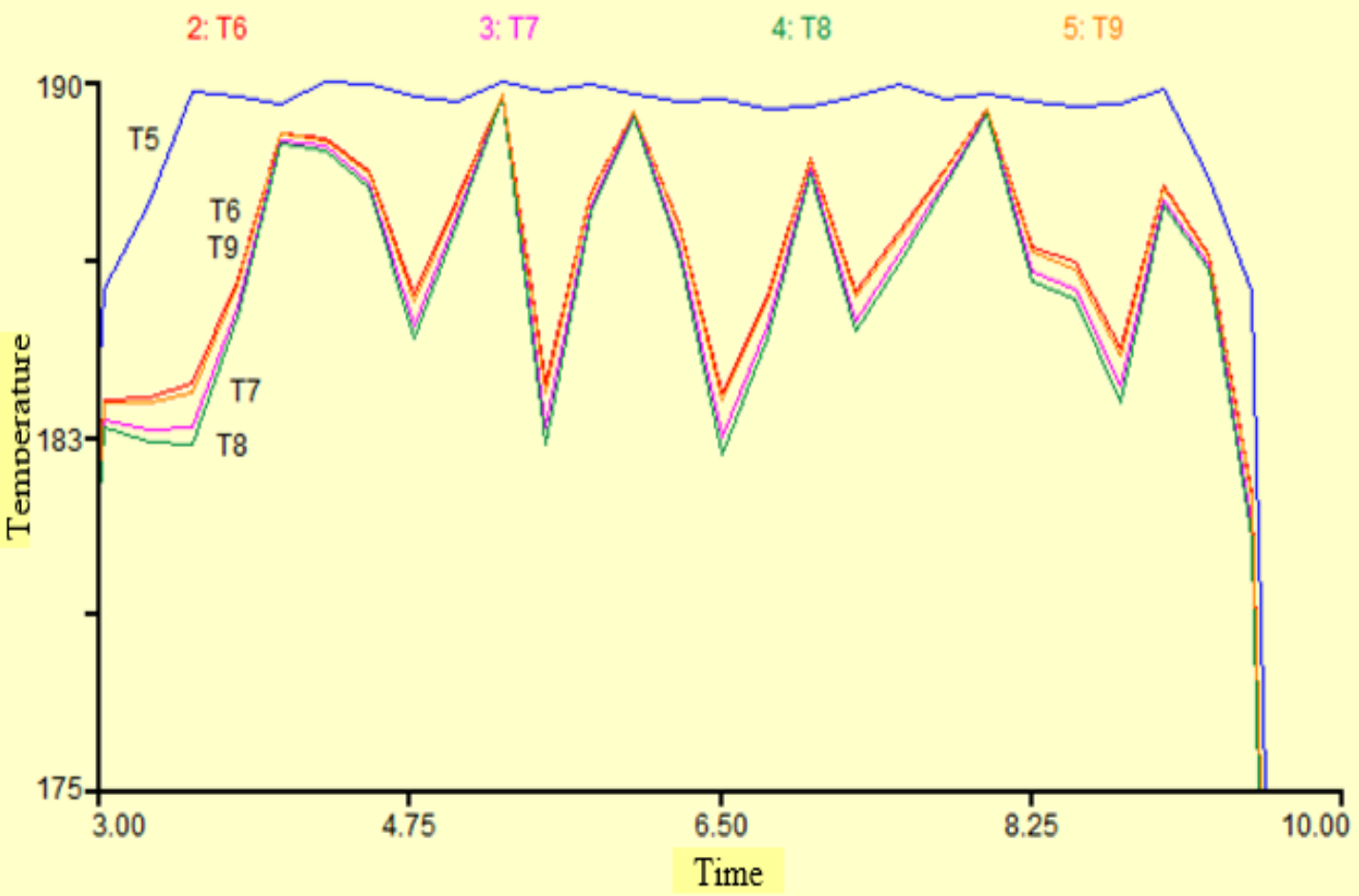

$\nabla$

$?$

Fig. 13. Mode of autoclave operation with open valves F5 and F10 
Having analyzed all the operating modes of the autoclave, it was found that the 1st operating mode of the autoclave is the most efficient since steam is supplied through all the valves and the heating of the autoclave is more uniform and faster. The 3rd mode of autoclave operation is less effective than the 1st since three pipelines are involved. Based on the fact that in the 3rd mode the steam is supplied to the upper part of the autoclave heating will occur more uniformly than in the 2nd, 4th and 5th modes. In the 4th mode, steam is supplied by two pipelines to the middle part of the autoclave gradually heating the left and the right parts, thus the difference in temperature values between the right and left parts of the autoclave will not be significant. The 5 th mode of autoclave operation is also less effective since steam is supplied to the left upper and right lower parts of the autoclave. With such a steam supply the heating of the entire space of the autoclave is very slow. The 2nd mode of operation is the worst since in this case the steam is supplied to the left side, the autoclave heats up rather slowly and unevenly and there are large temperature deviations: in the left part of the autoclave the sensors show a temperature of $190^{\circ} \mathrm{C}$ and in the right part $179^{\circ} \mathrm{C}$ [9].

\section{CONCLUSION}

The operation of the autoclave depends on many factors that can adversely affect the production of slag blocks, especially at certain production capacity.

From the analysis of the obtained models, it was revealed that, when steam is supplied uniformly to the entire space of the autoclave, heating occurs more evenly and faster - this allows us to reduce the amount of rejects in the slag blocks.

\section{REFERENCES}

[1] Muravyova E.A., Fuzzification concept using the any-time algorithm on the basis of precise term sets, Industrial Engineering, Applications and Manufacturing (ICIEAM): International Conference on Industrial Engineering, Applications and Manufacturing, 16-19 May 2017, IEEE. - SPb., 2017.

[2] Shebeko Yu.A., Guide on iThink analytical package., URL: http://www.tora-centre.ru/library/reing/ta.htm (date of reference: 15.05.2017). (in Russian)

[3] GOST 10037-83 - Autoclaves for construction industry., Technical specifications., M: Standard publishers, 1983, 33 p. (in Russian)

[4] M.B. Guzairov, E.A. Muravyova, Process control implemented on clear logic controllers, M.: Masinostroenie, 2012, 305p. (in Russian)

[5] Michasova O.V., Simulation of economic systems: study guide, Nizhny Novgorod: Nizhny Novgorod State University, 2014, pp. 159-171. (in Russian)

[6] Shebeko Yu.A., Guide on iThink analytical package. URL: http://www.tora-centre.ru/library/reing/ta.htm (date of reference: 15.05.2017). (in Russian)

[7] Kuznetsov Yu.A., Perova V.I., Application of simulation packages for the analysis of mathematical models of economic systems: study guide., Nizhny Novgorod, 2007, 98 p. (in Russian)

[8] Assessing the quality of a simulation model, URL: http://lifeprog.ru/1_995_otsenka-kachestva-imitatsionnoy-modeli.html (date of reference: 15.05.2017). (in Russian)

[9] Muravyova E.A., Sharipov M. I., Method of fuzzy controller adaptation, Proceedings of the International Conference "Actual Issues of Mechanical Engineering", 2017 (AIME 2017), November 2017. doi:10.2991/aime-17.2017.82. 